\title{
Pulmonary Microvascular Responses to Inhaled Prostacyclin, Nitric Oxide, and Their Combination in Anesthetized Cats
}

\author{
Soichiro IKEDA ${ }^{*} \dagger$, Mikiyasu SHIRAI ${ }^{*}$, Akito SHIMOUCHI ${ }^{*}$, Kyong-Yob MIN ${ }^{\dagger}$, \\ Nakaaki OHSAWA ${ }^{\dagger}$, and Ishio NINOMIYA ${ }^{\ddagger}$ \\ *Departments of Cardiac Physiology and Cardiovascular Dynamics, National Cardiovascular \\ Center Research Institute, Suita, 565-0873 Japan; ' ${ }^{\dagger}$ First Department of Internal Medicine, \\ Osaka Medical College, Takatsuki, 569-8686 Japan; and \$Department of Clinical \\ Engineering, Faculty of Health Sciences, Hiroshima International University, \\ Hiroshima, 724-0695, Japan
}

\begin{abstract}
Using an X-ray television system on anesthetized cats, we directly measured internal diameter (ID) changes in identical small pulmonary vessels $(100-1,100 \mu \mathrm{m}$ ID) in response to inhalations of 25,250 , and $2,500 \mathrm{ng} / \mathrm{kg} / \mathrm{min}$ aerosolized prostacyclin $\left(\mathrm{PGI}_{2}\right), 4$ and $34 \mathrm{ppm}$ nitric oxide (NO), and the combination of aerosolized $\mathrm{PGI}_{2}$ and $\mathrm{NO}$. We also compared ID changes during $250 \mathrm{ng} / \mathrm{kg} / \mathrm{min} \mathrm{PGI}_{2}$ inhalation both with and without an $\mathrm{N}^{\omega}$-nitro-L-arginine methyl ester (L-NAME, $30 \mathrm{mg} / \mathrm{kg}$ I.V.) pretreatment. In the arteries, inhaled $\mathrm{PGI}_{2}$ increased $100-900 \mu \mathrm{m}$ vessel ID in a dose-dependent manner but caused no significant, or only slight, ID increases in the vessels larger than this. The greatest ID increase $(\sim 22 \%)$ was in the 100 $500 \mu \mathrm{m}$ arteries in response to $2,500 \mathrm{ng} / \mathrm{kg} / \mathrm{min}$ $\mathrm{PGI}_{2}$ inhalation. $\mathrm{PGI}_{2}$ also increased the ID of the veins $(6-12 \%)$, but the results were not dose related. NO inhalation also resulted in non-uniform ID response patterns similar to $\mathrm{PGI}_{2}$ with no sig-
\end{abstract}

nificant, or only minimal, ID increases of the arteries $>900 \mu \mathrm{m}$. The simultaneous inhalation of $2,500 \mathrm{ng} / \mathrm{kg} / \mathrm{min} \mathrm{PGI}_{2}$ and $34 \mathrm{ppm}$ NO increased the arterial ID (maximum $\sim 34 \%$ ) more than either drug alone and to almost the same extent as brought about by injected papaverine $(2 \mathrm{mg} / \mathrm{kg})$, a smooth muscle relaxant. Inhaled $\mathrm{PGl}_{2}$ (250 $\mathrm{ng} / \mathrm{kg} / \mathrm{min}$ ) decreased pulmonary arterial pressure and increased arterial ID to nearly the same extent with or without L-NAME pretreatment. These results indicate that inhaled $\mathrm{PGI}_{2}$ and inhaled NO locally dilate $100-900 \mu \mathrm{m}$ pulmonary arteries in a dose-dependent manner and with a similar ID response pattern, and that the combination of these drugs produces a more enhanced vasodilator effect compared to their separate effects and induces the maximum dilated states. The data also suggest that inhaled $\mathrm{PGI}_{2}$ dilates these arteries directly, rather than via secondary release of endogenous NO. [Japanese Journal of Physiology, 49, 89-98, 1999]

Key words: aerosolized prostacyclin, nitric oxide, enhanced vasodilator effect, small pulmonary vessels, angiography.

Inhaled nitric oxide (NO) has been described as an effective pulmonary depressor in various experimental and clinical pulmonary hypertensive situations [1, 2]. Furthermore, we have recently provided direct evidence of the pulmonary vasodilator effects of inhaled NO by measuring pulmonary vascular internal diameter (ID) with an X-ray TV system [3].
Intravenous administration of prostacyclin $\left(\mathrm{PGI}_{2}\right)$, an arachidonic acid metabolite, has also been shown to decrease pulmonary arterial pressure [4] and increase the ID of small pulmonary arteries [5]. It has been applied in various clinical pulmonary hypertensive conditions [6]. However, systemic administration of $\mathrm{PGI}_{2}$ has a depressor effect in both pulmonary and 


\section{S. IKEDA et al.}

systemic circulation, usually leading to unfavorable systemic hypotension [7].

Recently, inhaled nebulized $\mathrm{PGI}_{2}$ has been attracting a great deal of attention as a selective pulmonary depressor which does not affect the systemic circulation [8]. Until now, however, no direct measurement of the ID has been carried out to determine which pulmonary vascular segment actually dilates in response to inhaled nebulized $\mathrm{PGI}_{2}$ or to reveal the differences between the vasodilator effects of inhaled NO and $\mathrm{PGI}_{2}$. Moreover, the effects of the simultaneous inhalation of these drugs have also not been investigated, although a few trials have been conducted with a combination of intravenous $\mathrm{PGI}_{2}$ and inhaled NO [9-11].

In this study, we investigated 1) the action sites of inhaled $\mathrm{PGI}_{2}$ and $\mathrm{NO}$ in the identical small pulmonary vessels $(100-1,100 \mu \mathrm{m}$ ID) of anesthetized cats by directly measuring their ID changes and 2) the vasodilator effects of the combined inhalation of $\mathrm{PGI}_{2}$ and $\mathrm{NO}$, and compared them with those of papaverine, a smooth muscle relaxant. In addition, we investigated the effect of a NO-synthase inhibitor on the vasodilation caused by inhaled $\mathrm{PGI}_{2}$ in order to examine whether endogenous $\mathrm{NO}$ mediates the $\mathrm{PGI}_{2}$-induced vasodilations [12].

\section{METHODS}

Experimental procedure and angiography. The experiments were carried out using 13 cats (2.0$4.1 \mathrm{~kg} \mathrm{bw})$. They were anesthetized with pentobarbital sodium $(35 \mathrm{mg} / \mathrm{kg}$ I.P.), and the level of anesthesia maintained with supplemental doses of pentobarbital sodium $(2-3 \mathrm{mg} / \mathrm{kg}$ I.V.) at $0.5-$ to 1 -h intervals. Each cat was intubated with an endotracheal tube and artificially ventilated with room air at a tidal volume of $10-12 \mathrm{ml} / \mathrm{kg}$ and a rate of $20-24$ cycles $/ \mathrm{min}$. The anesthesia and preparation of animals were performed in accordance with the Guiding Principles for the Care and Use of Animals approved by the Council of the Physiological Society of Japan.

A 4-F Swan-Ganz balloon-tip catheter (Edwards Labo.) was introduced fluoroscopically from the right jugular vein into the left main pulmonary artery. Two additional polyethylene catheters were also inserted into the right femoral artery and vein. The left-side rib cage (ribs 6-8) was partially excised to directly expose the left lower lobe to the X-ray. The end-expiratory pressure was adjusted to $4.0 \mathrm{cmH}_{2} \mathrm{O}$ to prevent lung collapse. Heparin was administered intravenously at a dose of $500 \mathrm{IU} / \mathrm{kg}$ to prevent blood coagulation in the catheters.
The system and the experimental setup for angiography have been described in detail previously [13]. In short, the cat was positioned within the X-ray apparatus box (Osaka Softex) and fixed so that the exposed left lower lung was automatically in contact with a plate just above the beryllium faceplate of an X-ray sensitive, 1-in. vidicon camera (Hamamatsu Photonics). The cat was partially covered with a heating pad to keep its rectal temperature at $37.5^{\circ} \mathrm{C}$. The temperature in the box was maintained at $25-28^{\circ} \mathrm{C}$, and the surface of the exposed lung was kept wet with warm $\left(37^{\circ} \mathrm{C}\right)$ saline. During the temporary cessation of ventilation at end-expiration, a contrast medium $(3-3.5 \mathrm{ml}$ of $60 \%$ Urografin, Schering) [14] was injected into the left main pulmonary artery through the catheter at a constant speed $(2.0 \mathrm{ml} / \mathrm{s})$. Before and during the injection of contrast medium, the fluoroscopic image was monitored on a television and recorded at a high speed of $30 \mathrm{frames} / \mathrm{s}$ on a videocassette recorder (PWW-2800, Sony). Blood gases and $\mathrm{pH}$ were frequently measured throughout the experiment by a blood gas analyzer (ABL2, Radiometer). Systemic arterial blood gases were $\mathrm{PaO}_{2} \quad 101 \pm 4$ Torr, $\mathrm{PaCO}_{2}$ $30 \pm 1$ Torr, and pH 7.39 \pm 0.01 under the baseline condition. These parameters were not significantly changed in response to $\mathrm{PGI}_{2}$ and $\mathrm{NO}$ inhalations and papaverine injection.

Measurement of ID. The serial angiograms recorded on the videocassette recorder were transferred to a digital image processor (TVIP-2000, Nippon Avionics). To obtain the angiogram for measuring ID, four serial frames, in which vascular trees were extensively filled with contrast medium, were added up and averaged by the digital image processor. This was done for both pulmonary arteries and veins. The processed image was clearly copied onto paper with an imaging hard copy unit (model 4634, Sony Tektronix), and the ID of the pulmonary vessels on the copy was measured manually using a digitizer (model 9874A, Hewlett-Packard) connected to a minicomputer.

Analysis of ID response. Following the method described in our previous study [15], a random selection of many vascular sites was made for the ID measurement. The ID percent change in response to inhaled $\mathrm{NO}$ and $\mathrm{PGI}_{2}$ was calculated against the initial baseline value at each measured vascular site. The measured sites were classified into three or five vascular groups with different ID sizes according to their initial baseline ID size.

Experimental protocol. Protocol 1: pulmonary vascular responses to inhaled $\mathrm{PGI}_{2}$ and $\mathrm{NO}$ : The baseline angiogram was recorded first, followed 
by the angiograms during 1) a nebulized glycine buffer inhalation, and 25,250 and $2,500 \mathrm{ng} / \mathrm{kg} / \mathrm{min}$ nebulized $\mathrm{PGI}_{2}$ inhalations, 2) 4 and 34 ppm NO inhalations, 3) simultaneous inhalation of $2,500 \mathrm{ng} / \mathrm{kg} /$ min $\mathrm{PGI}_{2}$ and $34 \mathrm{ppm} \mathrm{NO}$, and 4) a smooth muscle relaxant, papaverine hydrochloride $(2 \mathrm{mg} / \mathrm{kg}$, I.V.). In four of eight cats, the experiments were carried out in a 1$) \rightarrow 2) \rightarrow 3$ ) $\rightarrow 4$ ) order; and for the other four cats, in a 2) $\rightarrow 1) \rightarrow 3$ ) $\rightarrow$ ) order. There was an interval of more than $1 \mathrm{~h}$ between steps 1 ) and 2), and between steps 3 ) and 4). We confirmed that ID changes returned to their initial baseline level after these intervals.

The periods of $\mathrm{NO}$ and $\mathrm{PGI}_{2}$ exposure were $10 \mathrm{~min}$, because both substances brought about an immediate decrease in pulmonary arterial pressure which reached its lowest point within $10 \mathrm{~min}$. In the preliminary study, we found that the ID changes in response to 4-34 ppm NO inhalations returned to their initial baseline level $\sim 10 \mathrm{~min}$ after the inhalations ceased, and those in response to $25-2,500 \mathrm{ng} / \mathrm{kg} / \mathrm{min} \mathrm{PGI}_{2}$ inhalations returned $\sim 15 \mathrm{~min}$ after discontinuance. Therefore, an interval of $\sim 20 \mathrm{~min}$ between each inhalation was allowed to eliminate any influence of the preceding exposures. The angiogram with papaverine was obtained when pulmonary arterial pressure reached nearly the minimal level at $2-3 \mathrm{~min}$ after the injection ended.

Protocol 2: pulmonary vascular responses to inhaled $\mathrm{PGI}_{2}$ with and without $\mathrm{NO}$-synthase inhibition: Five of the thirteen cats were used in this protocol. The first paired angiograms were taken before and 10 min after the $250 \mathrm{ng} / \mathrm{kg} / \mathrm{min} \mathrm{PGI}_{2}$ inhalation. $\mathrm{PGI}_{2}$ was administered in the same manner as for protocol 1 . $\mathrm{N}^{\omega}$-nitro-L-arginine methyl ester (L-NAME, $30 \mathrm{mg} / \mathrm{kg}$ I.V., Sigma) was injected after checking that ID changes had returned to their initial levels. The angiogram with L-NAME was obtained 20 min after the injection, followed by the angiogram with L-NAME plus $10 \mathrm{~min}$ periods of $\mathrm{PGI}_{2}(250 \mathrm{ng} / \mathrm{kg} / \mathrm{min})$ inhalation.

Application of $\mathbf{P G l}_{2}$. For the inhalation of $\mathrm{PGI}_{2}$ in aerosol form, an ultrasonic nebulizer (NE-U11B, Omron, Kyoto, Japan) was connected between the ventilator and endotracheal tube. This nebulizer delivers aerosolized particles with an average diameter of $5 \mu \mathrm{m}$, which can therefore easily reach the lower respiratory tract. $\mathrm{PGI}_{2}$ was supplied as a sodium salt (Wako Pure Chem. Ind., Japan) dissolved in a glycine buffer of $\mathrm{pH} 10.6$ at 10,100 , and $1,000 \mu \mathrm{g} / \mathrm{ml}$ concentrations. These solutions were kept frozen at $-20^{\circ} \mathrm{C}$ until use. They were thawed on ice and diluted 10 times with $0.9 \%$ saline just before administration. Twenty milliliters of solution was poured into the neb- ulizer chamber.

Before the experiment, we estimated the amount of $\mathrm{PGI}_{2}$ to be administered by connecting a water trap containing moisture absorbents to an endotracheal tube, in place of the animal, and weighing the fluid which was absorbed after nebulization. Approximately $25 \mathrm{ng} / \mathrm{kg} / \mathrm{min} \mathrm{PGI}_{2}$ was delivered with this system when $1 \mu \mathrm{g} / \mathrm{ml} \mathrm{PGI}{ }_{2}$ was prepared in the chamber.

Application of NO. NO was delivered from a source tank of $812 \mathrm{ppm}$ in $\mathrm{N}_{2}$ (Takachiho, Tokyo, Japan). With the flow controller, a given concentration of $\mathrm{NO}$ at 4 and $34 \mathrm{ppm}$ was obtained by mixing with $\mathrm{N}_{2}$ and $\mathrm{O}_{2}$ while inspired $\mathrm{O}_{2}$ concentration $\left(\mathrm{FiO}_{2}\right)$ was maintained at $21 \%$. The NO gas mixture was supplied to the inspiratory circuit of the ventilator via a $1-l$ reservoir bag. The NO gas mixture passed through a tube filled with soda-lime to scavenge $\mathrm{NO}_{2}$ just before the inlet of the ventilator. The concentrations of the inspired $\mathrm{NO} / \mathrm{NO}_{2}$ were monitored at the endotracheal tube using a chemiluminescence $\mathrm{NO} / \mathrm{NO}_{2}$ analyzer (ECL-88US, Yanako, Kyoto, Japan). The inspired NO concentration decreased by less than $1 \mathrm{ppm}$ when $\mathrm{PGI}_{2}$ nebulizer was added to $34 \mathrm{ppm}$ inhaled NO. The inspired $\mathrm{NO}_{2}$ concentration was under $0.3 \mathrm{ppm}$ and did not change even when the nebulization was added.

Methemoglobin levels were $1.0 \pm 0.1 \%$ during 4 ppm NO, and increased to $1.3 \pm 0.2 \%$ during $34 \mathrm{ppm}$ NO $(p<0.05)$, but there was no difference in the methemoglobin level between $34 \mathrm{ppm}$ NO inhalation by itself and its combination with nebulized 2,500 $\mathrm{ng} / \mathrm{kg} / \mathrm{min} \mathrm{PGI}_{2}$.

\section{Contribution of pressure- and flow-sensing} mechanisms to ID changes in response to agents. In this study, mean pulmonary arterial pressure (PAP) was decreased by $2-4 \mathrm{mmHg}$ during $\mathrm{PGI}_{2}, \mathrm{NO}$, and $\mathrm{PGI}_{2}+\mathrm{NO}$ inhalations, and papaverine injection. It was therefore possible that the local pressure-sensing mechanism (see DISCUSSION) influenced the ID change pattern caused by these agents. To examine this possibility, we preliminarily measured the effect of mechanically-induced PAP decrease on the ID of small pulmonary vessels in four cats. Partial interruption of pulmonary blood flow with a balloon-tip catheter inserted into the vena cava inferior lowered PAP by $\sim 4 \mathrm{mmHg}$ below the baseline level, but caused no significant change in the small-vessel ID. This suggests that the possible influence of this mechanism is small.

We also examined the possibility that the local flow-sensing mechanism (see DISCUSSION) participated significantly in the ID changes caused by inhaled $\mathrm{PGI}_{2}$ and $\mathrm{NO}$, and injected papaverine. To do this, further preliminary experiments were carried out 
S. IKEDA et al.

Table 1. Hemodynamic data.

\begin{tabular}{|c|c|c|c|c|}
\hline \multirow{2}{*}{ Condition } & \multicolumn{2}{|c|}{$\operatorname{PAP}(\mathrm{mmHg})$} & \multicolumn{2}{|c|}{$\mathrm{SAP}(\mathrm{mmHg})$} \\
\hline & $\begin{array}{c}\text { Before } \\
\text { administration }\end{array}$ & $\begin{array}{c}\text { During } \\
\text { administration }\end{array}$ & $\begin{array}{c}\text { Before } \\
\text { administration }\end{array}$ & $\begin{array}{c}\text { During } \\
\text { administration }\end{array}$ \\
\hline \multicolumn{5}{|l|}{ Protocol $1(n=8)$} \\
\hline \multicolumn{5}{|l|}{ Aerosolized $\mathrm{PGI}_{2}$} \\
\hline $25 \mathrm{ng} / \mathrm{kg} / \mathrm{min}$ & $17.4 \pm 0.7$ & $15.4 \pm 0.7^{*}$ & $110 \pm 3$ & $108 \pm 3$ \\
\hline $250 \mathrm{ng} / \mathrm{kg} / \mathrm{min}$ & $16.8 \pm 0.9$ & $14.5 \pm 0.8^{\star}$ & $106 \pm 4$ & $97 \pm 4^{*}$ \\
\hline $2,500 \mathrm{ng} / \mathrm{kg} / \mathrm{min}$ & $16.3 \pm 0.9$ & $13.5 \pm 0.9^{*}$ & $101 \pm 2$ & $91 \pm 4^{*}$ \\
\hline \multicolumn{5}{|l|}{ NO } \\
\hline 4 ppm & $17.3 \pm 1.0$ & $15.0 \pm 1.5^{*}$ & $104 \pm 7$ & $103 \pm 8$ \\
\hline 34 ppm & $16.8 \pm 1.1$ & $13.7 \pm 1.2^{\star}$ & $105 \pm 7$ & $102 \pm 8$ \\
\hline \multicolumn{5}{|c|}{$2,500 \mathrm{ng} / \mathrm{kg} / \mathrm{min} \mathrm{PGI}_{2}+34 \mathrm{ppm} \mathrm{NO}$} \\
\hline & $16.4 \pm 0.8$ & $13.1 \pm 1.0^{*}$ & $100 \pm 3$ & $89 \pm 5^{*}$ \\
\hline Papaverine & $17.5 \pm 1.0$ & $14.0 \pm 1.1^{*}$ & $97 \pm 8$ & $68 \pm 9^{* *}$ \\
\hline \multicolumn{5}{|l|}{ Protocol $2(n=5)$} \\
\hline \multicolumn{5}{|c|}{ without L-NAME pretreatment } \\
\hline \multicolumn{5}{|c|}{ with L-NAME pretreatment } \\
\hline $250 \mathrm{ng} / \mathrm{kg} / \mathrm{min}$ & $21.0 \pm 1.0$ & $16.8 \pm 1.1^{*}$ & $121 \pm 7$ & $112 \pm 10$ \\
\hline
\end{tabular}

Values are means $\pm S E ; n$, number of animals; PAP, mean pulmonary arterial pressure; SAP, mean systemic arterial pressure. Significant difference from the condition before administration: ${ }^{\star} p<0.05,{ }^{\star \star} p<0.01$.

using the following two protocols in another four cats. Initially, changes in local blood flow velocity $(V)$ in the small pulmonary arteries were measured in response to $\mathrm{PGI}_{2}$ and $\mathrm{NO}$ inhalations, and papaverine injection. $V$ was obtained by measuring the distance that the leading edge of the contrast medium moved per $0.1 \mathrm{~s}$ [13] in $\sim 400-600 \mu \mathrm{m}$ arteries. We found that mean percent decreases in $V$ were $11,11,5$, and $8 \%$ in response to $\mathrm{PGI}_{2}(2,500 \mathrm{ng} / \mathrm{kg} / \mathrm{min})$, NO $(34 \mathrm{ppm})$, and $2,500 \mathrm{ng} / \mathrm{kg} / \mathrm{min} \mathrm{PGI}_{2}+34 \mathrm{ppm}$ NO inhalations, and papaverine $(2 \mathrm{mg} / \mathrm{kg})$ injection, respectively. Secondarily, the effect of mechanically-induced decrease in $V$ on the ID of $\sim 400-600 \mu \mathrm{m}$ pulmonary arteries was examined. $V$ was decreased by $20-30 \%$ without PAP decrease when blood flow to the left lung was partially interrupted. We found no significant ID changes in response to such $V$ decreases. From these data, we considered the contribution of the flow-mediated response to the present ID change to be small.

Statistical methods. Single comparisons were made as appropriate using Student's paired $t$-test, and multiple comparisons in hemodynamic data and ID responses for the different doses and drugs were made using analysis of variance followed by Tukey's multiple comparison test. ID response differences among the five vascular groups with different ID sizes were assessed in the same way. Significance was defined as $p<0.05$. All results are expressed as means $\pm \mathrm{SE}$.

\section{RESULTS}

\section{Responses to inhalations of $\mathrm{PGl}_{2}, \mathrm{NO}$, and their combination \\ Hemodynamic data. The values of PAP and} mean systemic arterial pressure (SAP) before and during the inhalation of $\mathrm{PGI}_{2}, \mathrm{NO}$, and their combination are summarized in Table 1. These parameters were obtained just before injection of the contrast medium. With 25,250 , and $2,500 \mathrm{ng} / \mathrm{kg} / \mathrm{min} \mathrm{PGI}_{2}$ nebulization, PAP decreased significantly by $2.0,2.3$, and 2.8 $\mathrm{mmHg}$, respectively. With 4 and $34 \mathrm{ppm}$ NO inhalations, PAP also decreased significantly by 2.3 and 3.1 $\mathrm{mmHg}$, respectively. During the inhalations of 250 and $2,500 \mathrm{ng} / \mathrm{kg} / \mathrm{min} \mathrm{PGI}_{2}$, SAP decreased significantly by 9 and $10 \mathrm{mmHg}$, respectively. On the other hand, NO inhalations caused no significant changes in SAP.

The combined inhalation of $2,500 \mathrm{ng} / \mathrm{kg} / \mathrm{min} \mathrm{PGI}_{2}$ and $34 \mathrm{ppm}$ NO decreased both PAP and SAP by 3.3 and $11 \mathrm{mmHg}$, respectively. In combination, they had a tendency to decrease PAP more than when administered individually, but this difference was not statistically significant. Papaverine injection significantly decreased PAP and SAP by 3.5 and $29 \mathrm{mmHg}$, respectively.

ID responses to $\mathrm{PGI}_{2}$ and $\mathrm{NO}$ inhalations. Figure 1 shows typical ID changes in the small pul- 


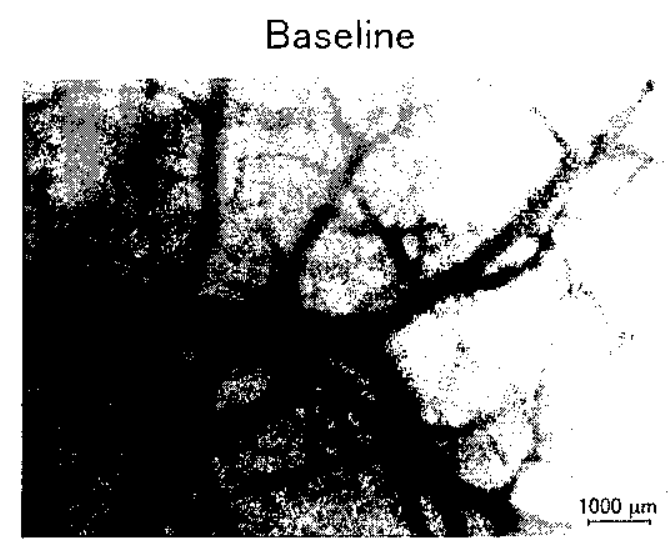

34 ppm NO

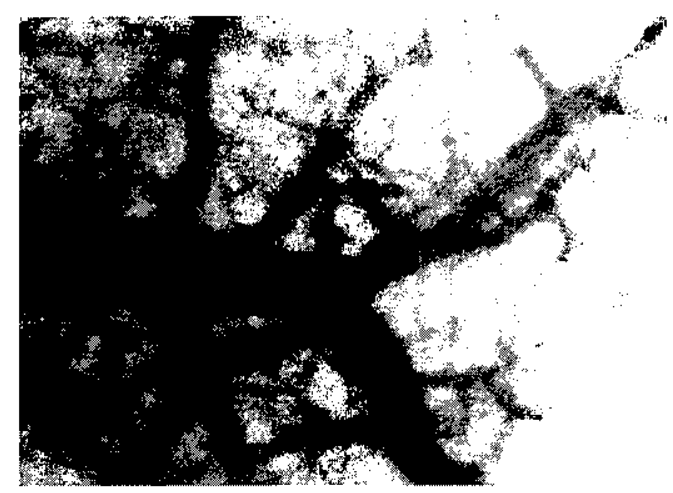

$2,500 \mathrm{ng} / \mathrm{kg} / \mathrm{min} \mathrm{PGI}_{2}$
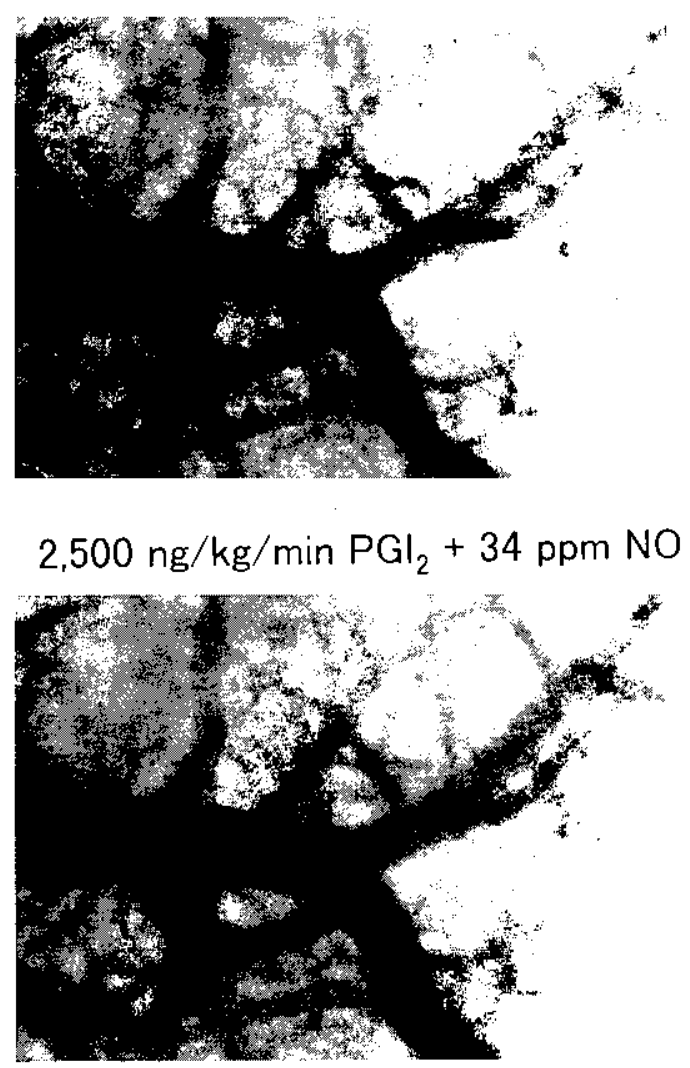

Fig. 1. Typical angiograms of small pulmonary arteries obtained before (top left) and during (top right) aerosolized 2,500 ng/kg/min $\mathrm{PGI}_{2}$ inhalation, $34 \mathrm{ppm} \mathrm{NO}$ inhalation (bottom left), and their simultaneous inhalation (bottom right) in the same cat.

monary arteries in response to inhalations of 2,500 $\mathrm{ng} / \mathrm{kg} / \mathrm{min} \mathrm{PGI}_{2}, 34 \mathrm{ppm} \mathrm{NO}$, and their combination in the same cat. With $\mathrm{PGI}_{2}$, and also with NO inhalation, the ID in many arterial branches obviously increased. When they were combined, the ID clearly increased more than when they were inhaled separately.

The relationship between vessel size and percent ID change in the small arteries and veins is shown in response to $\mathrm{PGI}_{2}$ inhalations (Fig. $2 \mathrm{~A}$ ) and NO inhalations (Fig. 2B). During $25 \mathrm{ng} / \mathrm{kg} / \mathrm{min} \mathrm{PGI}_{2}$ inhalation, the ID of $100-500 \mu \mathrm{m}$ arteries increased significantly. During the inhalation of 250 and $2,500 \mathrm{ng} / \mathrm{kg} / \mathrm{min}$ $\mathrm{PGI}_{2}$, the ID of these arteries increased further and the larger arteries $(500-900 \mu \mathrm{m})$ also dilated. However, the arteries $>900 \mu \mathrm{m}$ showed no significant increase in ID at any dose less than $2,500 \mathrm{ng} / \mathrm{kg} / \mathrm{min}$. The highest dose increased the ID minimally but significantly. The maximum ID increase $(\sim 22 \%)$ occurred in the $100-500 \mu \mathrm{m}$ arteries during $2,500 \mathrm{ng} / \mathrm{kg} / \mathrm{min} \mathrm{PGI}_{2}$ inhalation. In the veins, the ID of $100-700 \mu \mathrm{m}$ vessels increased during 25 and $250 \mathrm{ng} / \mathrm{kg} / \mathrm{min}$ inhalation. During $2,500 \mathrm{ng} / \mathrm{kg} / \mathrm{min} \mathrm{PGI}_{2}$ inhalation, the ID of $700-1,100 \mu \mathrm{m}$ veins also increased. However, the dose-response pattern was not as clear as in the case of arteries.

In response to the inhalation of a glycine buffer, which was used as a $\mathrm{PGI}_{2}$ solvent, neither the hemodynamic parameter nor the ID changed significantly.

NO inhalation also increased the ID of the small arteries and veins. In the arteries, dose-related ID increases were induced and the response pattern in the serially connected vessels was similar to that observed for inhaled $\mathrm{PGI}_{2}$. The arteries $>900 \mu \mathrm{m}$ showed no significant increase in ID with $4 \mathrm{ppm}$ NO and only a minimal, but significant, increase with $34 \mathrm{ppm}$ NO, whereas the ID of 100-900 $\mu \mathrm{m}$ arteries increased significantly with the two doses of NO. The inhaled 34 ppm NO increased the ID of these arteries to nearly the same extent as inhaled $2,500 \mathrm{ng} / \mathrm{kg} / \mathrm{min} \mathrm{PGI}_{2}$, with the maximum increase $(\sim 25 \%)$ in the $300-500 \mu \mathrm{m}$ arteries. In the veins, the $100-700 \mu \mathrm{m}$ vessels displayed significant ID increases, but the larger vessels did not.

The relationships between vessel size and ID percent change are compared between $\mathrm{PGI}_{2}$ and $\mathrm{NO}$, and their combined inhalation (Fig. 3A). In the arteries 
(A) Inhaled aerosolized $\mathrm{PGI}_{2}$

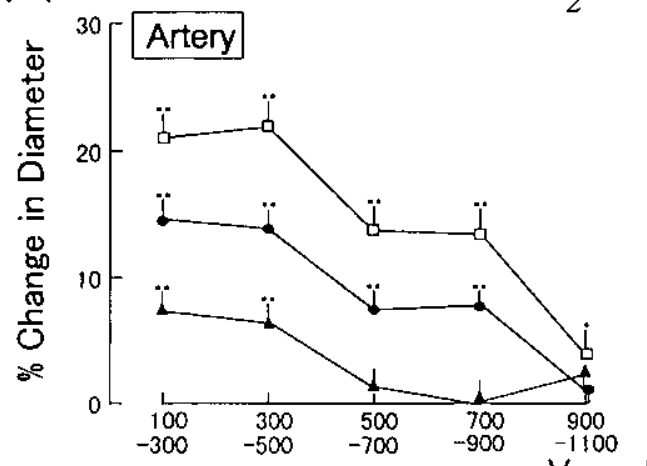

(B) Inhaled NO

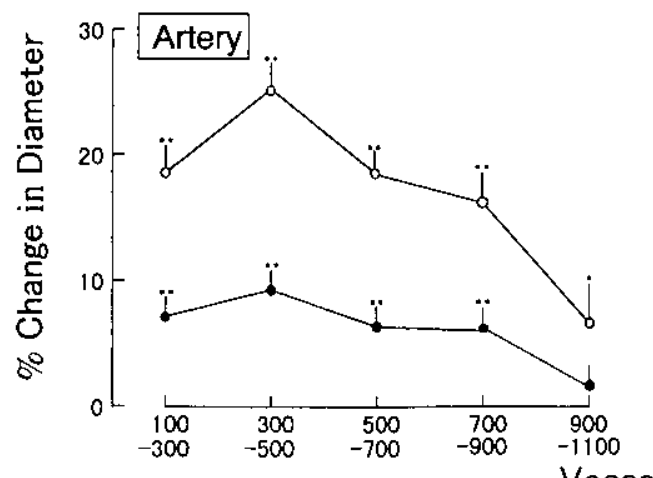

Vessel Size $(\mu \mathrm{m})$

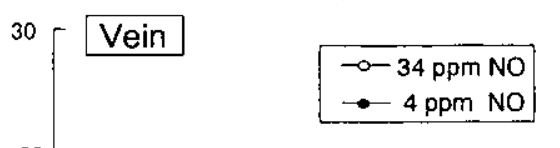

20
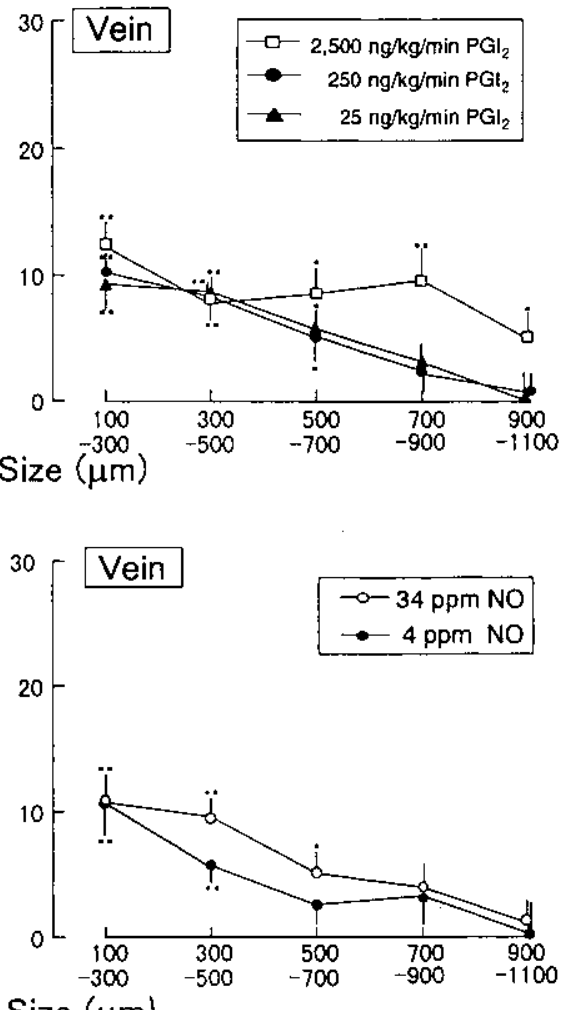

Fig. 2. Percent changes in internal diameter (ID) at different serial segments of small pulmonary arteries and veins in response to aerosolized $\mathrm{PGI}_{2}$ (A) and $\mathrm{NO}$ (B) inhalations. Numbers of measured sites in five vascular groups, i.e., 100-300, 300-500, 500-700, 700-900, 900-1,100 $\mu \mathrm{m}$, are $105,103,73,40$, and 30 , respectively, in the arteries. They are $74,73,39,28$, and 22 , respectively, in the veins. Significant ID increase from baseline value: ${ }^{*} p<0.05$, ${ }^{\star \star} p<0.01$.
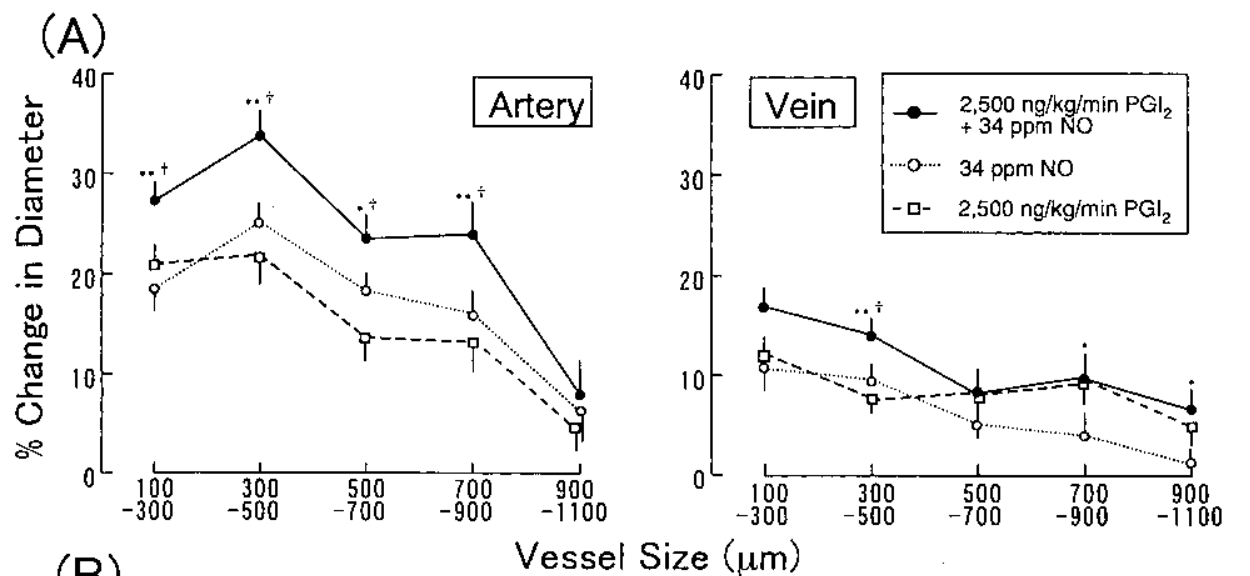

(B)

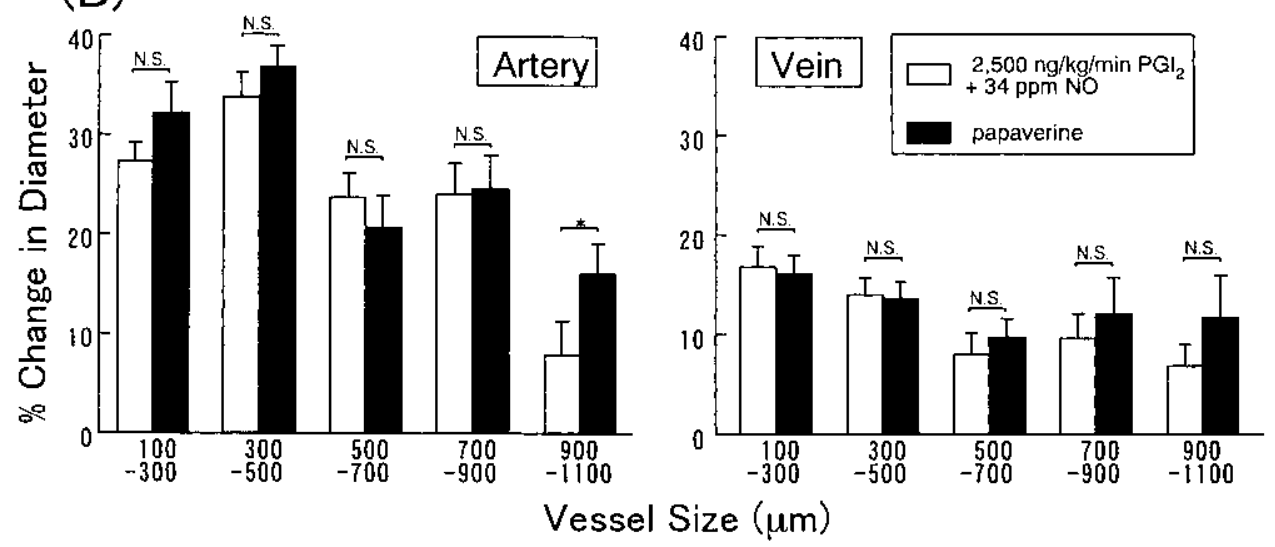

Fig. 3. Percent ID changes in response to the combined inhalation of $2,500 \mathrm{ng} / \mathrm{kg} /$ min $\mathrm{PGI}_{2}$ and $34 \mathrm{ppm} \mathrm{NO}$ are compared with those during their separate inhalations (A), and with those after papaverine injection (B). Numbers of measured sites in five vascular groups are the same as those in Fig. 2 . ${ }^{*} p<0.05, \quad{ }^{* *} p<0.01 \quad$ compared with NO alone; ${ }^{\dagger} p<0.01$ compared with $\mathrm{PGl}_{2}$ alone. 


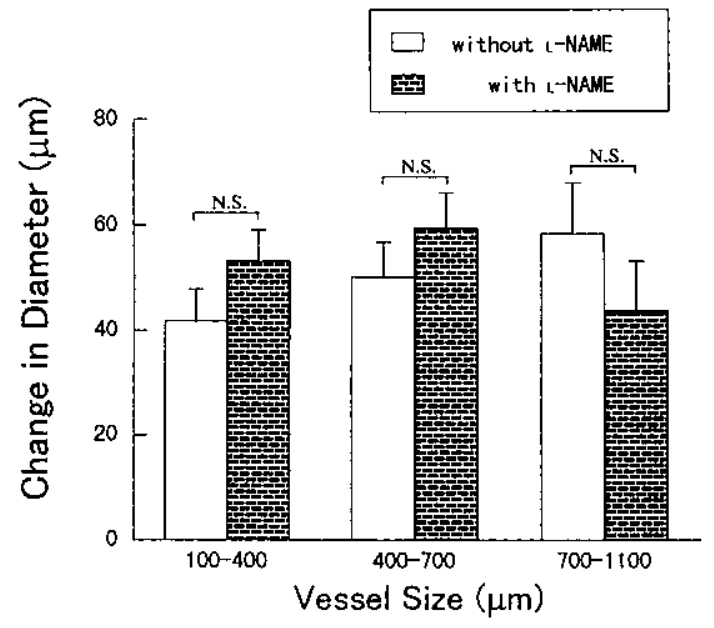

Fig. 4. Absolute ID changes at different serial segments of pulmonary arteries in response to aerosolized $250 \mathrm{ng} / \mathrm{kg} / \mathrm{min} \mathrm{PGI}_{2}$ inhalations with and without LNAME pretreatment. Number of measured sites in three vascular groups, i.e., 100-400, 400-700, 700-1,100 $\mathrm{m}$, are 76,79 , and 75 , respectively.

ranging from 100 to $900 \mu \mathrm{m}$, the combination of $2,500 \mathrm{ng} / \mathrm{kg} / \mathrm{min} \mathrm{PGI}{ }_{2}$ and $34 \mathrm{ppm}$ NO inhalations increased the ID more than either drug alone. However, such enhanced effects were not seen in arteries larger than this. The maximum ID increase $(\sim 34 \%)$ in response to the combined inhalation was observed also in the $300-500 \mu \mathrm{m}$ arteries.

The magnitudes of ID increase are compared between the simultaneous inhalation of $2,500 \mathrm{ng} / \mathrm{kg} / \mathrm{min}$ $\mathrm{PGI}_{2}$ and $34 \mathrm{ppm} \mathrm{NO}$, and the injection of papaverine (Fig. 3B). There were no significant differences between them in $100-900 \mu \mathrm{m}$ arteries and $100-1,100$ $\mu \mathrm{m}$ veins. In the $900-1,100$ arteries, however, the ID increase due to papaverine injection was significantly greater than that due to simultaneous inhalation.

\section{Responses to $\mathbf{P G l}_{2}$ with and without pre- treatment of L-NAME}

Hemodynamic data. The effects of $250 \mathrm{ng} / \mathrm{kg} /$ min $\mathrm{PGI}_{2}$ inhalations with and without L-NAME pretreatment are shown in Table1. Both PAP and SAP increased in response to L-NAME injection by 2.8 and $17 \mathrm{mmHg}$, respectively. The $250 \mathrm{ng} / \mathrm{kg} / \mathrm{min} \mathrm{PGI}_{2}$ inhalation with L-NAME decreased PAP to nearly the same extent as that without L-NAME.

ID responses. On average, the L-NAME injection decreased the ID of arteries to $\sim 87 \%$ of the initial level. The absolute values of the arterial ID increases in response to $250 \mathrm{ng} / \mathrm{kg} / \mathrm{min} \mathrm{PGI}_{2}$ inhalation were not significantly different between the conditions with and without L-NAME pretreatment (Fig. 4).

\section{DISCUSSION}

Using an X-ray TV system [13], we quantitatively measured the effects of inhaled $\mathrm{PGI}_{2}$, NO and their combination on the ID of identical feline small pulmonary vessels $(100-1,100 \mu \mathrm{m}$ ID) in vivo. In addition, we investigated the effects of NO-synthase inhibition on ID response to inhaled $\mathrm{PGI}_{2}$.

Action sites of inhaled $\mathrm{PGI}_{2}$ and $\mathrm{NO}$. $\mathrm{PGI}_{2}$ has been shown to decrease pulmonary and systemic arterial pressure in a dose-related manner when administered by injection $[4,16]$. But with this systemic depression, an increase in intrapulmonary shunt and hypoxemia limit the clinical application of $\mathrm{PGI}_{2}$ [8]. It was to overcome these demerits that aerosolized inhaled $\mathrm{PGI}_{2}$ was designed [8]. Previous studies have shown that inhaled $\mathrm{PGI}_{2}$, like inhaled $\mathrm{NO}$, is an effective depressor for pulmonary hypertension not only in experimental models of alveolar hypoxia $[8,17]$ and acute respiratory failure [18], but also in clinical cases of acute respiratory distress syndrome in adults [19-23] and children [24], and primary pulmonary hypertension [7] and congenital heart disease in newborns [25]. However, the difference in the action sites of $\mathrm{PGI}_{2}$ and $\mathrm{NO}$ in the serially connected pulmonary vessels has not been clarified.

In this study, we directly measured ID changes in feline small pulmonary vessels $(100-1,100 \mu \mathrm{m})$, which have rich smooth muscle layers [26, 27], in response to the inhalation of $\mathrm{PGI}_{2}$ and $\mathrm{NO}$. We found that, in the arteries, $25-2,500 \mathrm{ng} / \mathrm{kg} / \mathrm{min} \mathrm{PGI}_{2}$ inhalations caused non-uniform ID increases within the serially connected vessels and dose-related ID increases at the different serial segments (Fig. 2A). Although $25 \mathrm{ng} / \mathrm{kg} / \mathrm{min} \mathrm{PGI}_{2}$ inhalations only increased the ID of $100-500 \mu \mathrm{m}$ arteries, $2,500 \mathrm{ng} / \mathrm{kg} / \mathrm{min} \mathrm{PGI}_{2}$ acted on arteries over a wider range $(100-900 \mu \mathrm{m})$ and with greater effect. However, the responses in $900-1,100$ $\mu \mathrm{m}$ arteries were either very small or nonexistent. We also found that NO inhalation caused non-uniform ID increases in patterns similar to $\mathrm{PGI}_{2}$ (Fig. 2, A and B); no significant, or only minimal, ID increases were induced in the arteries $>900 \mu \mathrm{m}$. Intravenous infusion of papaverine, a smooth muscle relaxant, dilated the arteries $>900 \mu \mathrm{m}$ more greatly than inhaled $\mathrm{PGI}_{2}$, NO, and their combination (Fig.3, A and B). Therefore, the minimal vasodilation in the larger arteries cannot be ascribed to a diminution in relaxant ability of vascular smooth muscles in the region of $1,000 \mu \mathrm{m}$ in diameter. One possible reason is the failure of inhaled NO and $\mathrm{PGI}_{2}$ to directly diffuse into the smooth muscle cells of the arteries $>900 \mu \mathrm{m}$.

Inhaled $\mathrm{PGI}_{2}(25-250 \mathrm{ng} / \mathrm{kg} / \mathrm{min})$ and NO signifi- 
cantly increased the ID of $100-700 \mu \mathrm{m}$ veins, but the ID increase was not dose-related, in contrast to the arterial response. The reasons for the difference in the dose-response pattern between the artery and vein remain to be elucidated. However, papaverine increased the venous ID far less than the arterial ID (Fig. 3B), suggesting more dilated states in the vein than in the artery under baseline conditions. One of the reasons may be a difference in initial vascular tone between these vessels.

Inhaled $\mathrm{PGI}_{2}$ is used as a selective pulmonary depressor which does not affect the system circulation. However, a few previous studies have reported that a large dose of inhaled $\mathrm{PGI}_{2}$ also decreased [21], or had a tendency to decrease [17], systemic vascular resistance. In our study, significant SAP decreases were observed in response to 250 and $2,500 \mathrm{ng} / \mathrm{kg} / \mathrm{min}$ $\mathrm{PGI}_{2}$ (Table 1). In addition, $2,500 \mathrm{ng} / \mathrm{kg} / \mathrm{min} \mathrm{PGI}_{2}$ increased the ID of the larger veins $(700-1,100 \mu \mathrm{m})$, although the smaller doses of $\mathrm{PGI}_{2}$ did not (Fig. 2). During NO inhalations, in contrast, similar effects were not observed. Such differences may be explained by the data showing that $\mathrm{NO}$ becomes inactive within seconds due to binding tightly to hemoglobin [28], while $\mathrm{PGI}_{2}$ has a longer half-life $(2-3 \mathrm{~min})$ and does not become inactive while passing through the lung $[29,30]$, therefore, it may "spill over" [19] into the pulmonary veins and systemic vessels.

Blood vessels are sensitive to local changes in intraluminal pressure [31] and flow velocity $(V)$ [32, 33]. The pressure-dependent response to a rapid change in transmural pressure has been reported to take $15-30 \mathrm{~s}$ to become fully established [31]. The flow-mediated response reaches a maximum in $\sim 50 \mathrm{~s}$ after the onset of $V$ increase [32, 33]. In this study, there were PAP decreases of $2-4 \mathrm{mmHg}$ (Table 1) and $V$ decreases of $5-11 \%$ (see METHODS) when the angiograms were recorded $\sim 10 \mathrm{~min}$ after $\mathrm{PGI}_{2}, \mathrm{NO}$, or $\mathrm{PGI}_{2}+\mathrm{NO}$ inhalation, and $\sim 3 \mathrm{~min}$ after papaverine injection. It is therefore possible that the pressure- and flow-mediated responses became fully established and influenced the ID change caused by these agents. However, we found no significant ID changes when PAP was mechanically decreased by $\sim 4 \mathrm{mmHg}$ and $V$ by $20-30 \%$ (see METHODS). This suggests that the possibility is small and that direct actions of these substances on the small pulmonary vessels are the primary cause of the present ID change.

Enhanced dilator effect of inhaled $\mathrm{PGI}_{2}$ and NO on pulmonary arteries. A few previous studies have reported that the combination therapy of intravenous $\mathrm{PGI}_{2}$ and $\mathrm{NO}$ inhalation was more effective in lowering PAP than either drug by itself in a neonate with persistent pulmonary hypertension [9] and congenital aortic stenosis [10], and in pigs with pulmonary hypertension [11]. However, the effects of an inhaled $\mathrm{PGI}_{2}$ and $\mathrm{NO}$ combination on the pulmonary vessels was still to be investigated.

In this study, we first demonstrated that the simultaneous administration of inhaled $2,500 \mathrm{ng} / \mathrm{kg} / \mathrm{min} \mathrm{PGI}_{2}$ and $34 \mathrm{ppm}$ NO induced greater ID increases in small pulmonary arteries $(100-900 \mu \mathrm{m})$ than when the drugs were administered separately (Fig. 3A). The inhalation of 5-40 ppm NO has been reported to induce the maximum pulmonary depressor effect $[11,17]$. In the preliminary experiments, we confirmed that 34 ppm NO inhalation increased ID to almost the same extent as $84 \mathrm{ppm}$ NO inhalation. The inhalation of $2,500 \mathrm{ng} / \mathrm{kg} / \mathrm{min} \mathrm{PGI}_{2}$ would have extensively activated the pulmonary vessels in our preparations, because it did spill over into the systemic circulation to decrease SAP significantly (Table 1). These data mean that, when $\mathrm{PGI}_{2}$ inhalation was added to the maximally effective dose of inhaled NO, even further vasodilation of the small arteries occurred. This more enhanced vasodilator effect, compared with the separate effects, may be explained by the fact that these agents relax the vascular smooth muscles through two different second-messenger systems; $\mathrm{PGI}_{2}$ stimulates the cAMP pathway, whereas NO activates the cGMP pathway $[34,35]$. We also found that the combination of $2,500 \mathrm{ng} / \mathrm{kg} / \mathrm{min} \mathrm{PGI}_{2}$ and $34 \mathrm{ppm}$ NO inhalations increased the ID of the small arteries and veins almost as much as papaverine $(2 \mathrm{mg} / \mathrm{kg})$. Preliminary dose response experiments showed that the maximum response is achieved with this dose of papaverine. These findings suggest the possibility that this combination is able to induce maximum dilated states in small pulmonary vessels. It is noteworthy that papaverine relaxes vascular smooth muscles by inhibiting cyclic nucleotide phosphodiesterases and accumulating both cGMP and CAMP $[36,37]$.

The combination of $\mathrm{PGI}_{2}$ and $\mathrm{NO}$ inhalations may be applicable to clinical cases. In the three previous studies on the combination of intravenous $\mathrm{PGI}_{2}$ and inhaled NO [9-11], there was an inevitable decrease in SAP because of the intravenous $\mathrm{PGI}_{2}$ effects on systemic circulation. However, nebulized $\mathrm{PGI}_{2}$ inhalation at an appropriate dose can spare this unfavorable effect, and its combination with inhaled NO seems to be a better selective pulmonary vasodilator than the combination of intravenous $\mathrm{PGI}_{2}$ and inhaled NO.

Inhaled $\mathbf{P G I}_{2}$ dilates small pulmonary arteries with its own direct effect. Using pig vessels, Shimokawa et al. have showed that $\mathrm{PGI}_{2}$ relaxation is potentiated by the presence of the vascular en- 
dothelium and that this phenomenon is heterogenous: endothelium-dependent potentiation being clearest in coronary and basilar arteries but not in the carotid artery [12]. They have suggested that prostacyclin not only acts directly on the vascular smooth muscle cells but also stimulates endothelium-derived relaxing factor $(\mathrm{EDRF})$ release. Other researchers have reported that exogenously administered $\mathrm{PGI}_{2}$ does not cause endothelium-dependent relaxation in canine intrapulmonary arteries [38] or in the pig aorta [39] .

To examine whether endogenous NO is involved when inhaled $\mathrm{PGI}_{2}$ dilates the small pulmonary arteries in vivo, we investigated the effect of inhaled $\mathrm{PGI}_{2}$ during NO-synthase inhibition. The L-NAME administration per se elevated PAP significantly (Table 1) and decreased the ID of the small pulmonary arteries to $\sim 87 \%$ on average, which suggests that endogenous NO affects the basal vascular tone in pulmonary arteries. However, inhaled $250 \mathrm{ng} / \mathrm{kg} / \mathrm{min} \mathrm{PGI}_{2}$ with LNAME pretreatment decreased PAP just as effectively as without it (Table 1). Likewise, no significant difference was observed in ID responses to $250 \mathrm{ng} / \mathrm{kg} / \mathrm{min}$ $\mathrm{PGI}_{2}$ with or without L-NAME (Fig. 4). These data suggest that $\mathrm{PGI}_{2}$ dilates small pulmonary arteries mainly via direct action on the vascular smooth muscle, rather than via the endothelial release of NO stimulated by $\mathrm{PGI}_{2}$. This is consistent with the fact that adding inhaled $\mathrm{PGI}_{2}$ to the maximally effective dose of inhaled NO caused further vasodilation of the small pulmonary arteries (Fig. 3A).

In summary, the results indicate that, in anesthetized cats, both inhaled $\mathrm{PGI}_{2}$ and inhaled NO locally dilate small pulmonary arteries ranging from 100 to $900 \mu \mathrm{m}$ ID. These drugs caused similar nonuniform vasodilator patterns in serially connected arteries and dose-related dilations at different serial segments, the maximum dilation being in $\sim 100-500 \mu \mathrm{m}$ arteries. An enhanced vasodilator effect was obtained when they were administered simultaneously. Moreover, the data suggest that inhaled $\mathrm{PGI}_{2}$ dilates the pulmonary arteries mainly via its direct effect on the vascular smooth muscle, rather than via secondary NO release.

This study was supported, in part, by a grant from the Science and Technology Agency of Japan and by a research grant for Cardiovascular Diseases from the Ministry of Health and Welfare of Japan.

\section{REFERENCES}

1. Frostell C, Fratacci MD, Wain JC, Jones R, and Zapol WM: Inhaled nitric oxide: a selective pulmonary vasodilator reversing hypoxic pulmonary vasoconstric- tion. Circulation 83: 2038-2047, 1991

2. Pepke-Zaba J, Higenbottam TW, Dinh-Xuan AT, Stone $D$, and Wallwork J: Inhaled nitric oxide as a cause of selective pulmonary vasodilation in pulmonary hypertension. Lancet 338: 1173-1174, 1991

3. Shirai $M$, Shimouchi A, Kawaguchi AT, Sunagawa $K$, and Ninomiya I: Inhaled nitric oxide: diameter response patterns in feline small pulmonary arteries and veins. Am J Physiol 270 (Heart Circ Physiol 39): H974-H980, 1996

4. Kadowitz PJ, Chapnick BM, Feigen LP, Hyman AL, Nelson PK, and Spannhake EW: Pulmonary and systemic vasodilator effects of the newly discovered prostaglandin, $\mathrm{PGI}_{2}$. J Appl Physiol 45: 408-413, 1978

5. Sada $K$, Shirai $M_{1}$ and Ninomiya : Effects of prostaglandin $F_{2 \alpha}$ and prostacyclin on pulmonary microcirculation in the cat. J Appl Pysiol 62: 1124-1132, 1987

6. Rubin LJ, Groves BM, Reeves JT, Frosolono M, Handel $F$, and Cato AE: Prostacyclin-induced acute pulmonary vasodilation in primary pulmonary hypertension. Circulation 66: 334-338, 1982

7. Olschewski $H$, Walmrath D, Schermuly R, Ghofrani HA Grimminger $F$, and Seeger W: Aerosolized prostacyclin and iloprost in severe pulmonary hypertension. Ann Intern Med 124: 820-824, 1996

8. Welte $M$, Zwissler $B$, Habazettl $H$, and Messmer $K$ : $\mathrm{PGI}_{2}$ aerosol versus nitric oxide for selective pulmonary vasodilation in hypoxic pulmonary vasoconstriction. Eur Surg Res 25: 329-340, 1993

9. Parker TA, Ivy DD, Kinsella JP, Torielli F, Ruyle SZ, Thilo $\mathrm{EH}$, and Abman SH: Combined therapy with inhaled nitric oxide and intravenous prostacyclin in an infant with alveolar-capillary dysplasia. Am J Respir Crit Care Med 155: 743-746, 1997

10. Schranz D, Huth R, Wippermann CF, Ritzerfeld $S$, Schmitt FX, and Oelert H: Nitric oxide and prostacyclin lower suprasystemic pulmonary hypertension after cardiopulmonary bypass. Eur J Pediatr 152: 793-796, 1993

11. Van Obbergh LJ, Charbonneau M, and Blaise G: Combination of inhaled nitric oxide with I.V. nitroglycerin or with a prostacyclin analogue in the treatment of experimental pulmonary hypertension. $\mathrm{Br} J$ Anaesth 77: 227-231, 1996

12. Shimokawa $H$, Flavahan $N A$, Lorenz RR, and Vanhoutte PM: Prostacyclin releases endothelium-derived relaxing factor and potentiates its action in coronary arteries of the pig. Br J Pharmacol 95, 1197-1203, 1988

13. Sada $K$, Shirai $M$, and Ninomiya I: X-ray TV system for measuring microcirculation in small pulmonary vessels. J Appl Physiol 59: 1013-1018, 1985

14. Shirai M, Ninomiya I, and Sada K: Constrictor response of smail pulmonary arteries to acute pulmonary hypertension during left arterial pressure elevation. Jpn J Physiol 41: 129-142, 1991

15. Shirai M, Sada K, and Ninomiya I: Effects of regional alveolar hypoxia and hypercapnia on small pulmonary vessels in cats. J Appl Physiol 61: 440-448, 1986

16. Hyman AL and Kadowitz PJ: Pulmonary vasodilator activity of prostacyclin $\left(\mathrm{PG}_{2}\right)$ in the cat. Circ Res 45 : 404-409, 1979 


\section{S. IKEDA et al.}

17. Booke M, Bradford DW, Hinder F, Harper D, Brauchle RW, Traber LD, and Traber DL: Effects of inhaled nitric oxide and nebulized prostacyclin on hypoxic pulmonary vasoconstriction in anesthetized sheep. Crit Care Med 24: 1841-1848, 1996

18. Zobel G, Dacar D, Rödl S, and Friehs I: Inhaied nitric oxide versus inhaled prostacyclin and intravenous versus inhaled prostacyclin in acute respiratory failure with pulmonary hypertension in piglets. Pediatr Res 38: 198-204, 1995

19. Bein T, Metz C, Keyl C, Sendtner E, and Pfeifer M: Cardiovascular and pulmonary effects of aerosolized prostacyclin administration in severe respiratory failure using a ventilator nebulization system. J Cardiovasc Pharmacol 27: 583-586, 1996

20. Van Heerden PV, Webb SAR, Hee G, Corkeron M, and Thompson WR: Inhaled aerosolized prostacyclin as a selective pulmonary vasodilator for the treatment of severe hypoxaemia. Anaesth Intens Care 24: 87-90, 1996

21. Walmrath D, Schneider T, Pilch J, Grimminger F, and Seeger $W$ : Aerosolised prostacyclin in adult respiratory distress syndrome. Lancet 342: 961-962, 1993

22. Walmrath D, Schneider T, Schermuly R, Olschewski $H$, Grimminger $F$, and Seeger $W$ : Direct comparison of inhaled nitric oxide and aerosolized prostacyclin in acute respiratory distress syndrome. Am J Respir Crit Care Med 153: 991-996, 1996

23. Zwissler $B$, Kemming $G$, Habler $O$, Kleen M, Merkel M, Haller $M$, Briegel $J$, Welte $M$, and Peter $K$ : Inhaled prostacyclin $\left(\mathrm{PGl}_{2}\right)$ versus inhaled nitric oxide in aduit respiratory distress syndrome. Am J Respir Crit Care Med 154: 1671-1677, 1996

24. Pappert D, Busch T, Gerlach H, Lewandowski K, Radermacher $P$, and Rossaint R: Aerosolized prostacyclin versus inhaled nitric oxide in children with severe acute respiratory distress syndrome. Anesthesiology 82: 1507-1511, 1995

25. Zwissler $B$, Rank $N$, Jaenicke $U$, Schürler $B$, Welte $M$, Reichart B, Netz H, Messmer K, and Peter K: Selective pulmonary vasodilation by inhaled prostacyclin in a newborn with congenital heart disease and cardiopulmonary bypass. Anesthesiology 82: 1512-1516, 1995

26. Fishman AP: Respiratory gases in the regulation of the pulmonary circulation. Physiol Rev 41: 214-280, 1961
27. Sobin SS, Intaglietta M, Frasher WG Jr, and Tremer HM: The geometry of the pulmonary microcirculation. Angiology 17: 24-30, 1966

28. Rimar $\mathrm{S}$ and Gillis $\mathrm{CN}$ : Selective puimonary vasodilation by inhaled nitric oxide is due to hemoglobin inactivation. Circulation 88: 2884-2887, 1993

29. Dusting GJ, Moncada S, and Vane JR: Recirculation of prostacyclin $\left(\mathrm{PGI}_{2}\right)$ in the dog. Br $\mathrm{J}$ Pharmacol 64: 315-320, 1978

30. Hawkins HJ, Smith JB, Nicolaou KC, and Eling TE: Studies of the mechanisms involved in the fate of prostacyclin $\left(\mathrm{PGI}_{2}\right)$ and 6-keto-PGF ${ }_{1 \alpha}$ in the pulmonary circulation. Prostaglandins 16: 871-884, 1978

31. Folkow B: Introduction and historical background. J Hypertens 7 (Suppl 4): S1-\$4,1989

32. Koller A and Kaley G: Endothelium regulates skeletal muscle microcirculation by a blood flow velocity-sensing mechanism. Am J Physiol 258 (Heart Circ Physiol 27): H916-H920, 1990

33. Smiesko V, Lang DJ, and Johnson PC: Dilator response of rat mesenteric arcading arterioles to increased blood flow velocity: Am J Physiol 257 (Heart Circ Physiol 26): H1958-H1965, 1989

34. Rapoport RM and Murad F: Agonist-induced endothelium-dependent relaxation in rat thoracic aorta may be mediated through cGMP. Circ Res 52: 352-357, 1983

35. Walter $U$, Waldmann $R$, and Nieberding $M$ : Intracellular mechanism of action of vasodilators. Eur Heart $J 9$ : $\mathrm{H} 1-\mathrm{H} 6,1988$

36. Kramer GL and Wells JN: Effects of phosphodiesterase inhibitors on cyclic nucleotide levels and relaxation of pig coronary arteries. Mol Pharmacol 16: 813-822, 1979

37. Miyamoto $M$, Takayanagi $I$, Onkubo $H_{1}$ and Takagi $K$ : Actions of papaverine on intestinal smooth muscle and its inhibition of cyclic AMP and cyclic GMP phosphodiesterases. Jpn J Pharmacol 26: 114-117, 1976

38. Chand $\mathrm{N}$ and Altura BM: Acetylcholine and bradykinin relax intrapuimonary arteries by acting on endothelial cells: role in lung vascular diseases. Science 213 1376-1379, 1981

39. Gordon $\mathrm{JL}$ and Martin W: Stimulation of endothelial prostacyclin production plays no role in endotheliumdependent relaxation of the pig aorta. $\mathrm{Br} J$ Pharmacol 80: 179-186, 1983 